\title{
Pollution Performance of RTV Coated Insulators
}

\author{
Rajini. H, K. N. Ravi,Vasudev. N
}

\begin{abstract}
Theincrease in power demand necessitates the usage of $\mathrm{EHV}$ and $\mathrm{UHV}$ transmission system. The growth of industries causes higher pollution level in the ambient condition on insulators. This increases the pollution severity of the site which results in pollution accumulation on the surface of Insulators. This causes flashover across insulator. Flashover across polluted insulators poses a serious threat to the reliability of the system and leads to system outages. There are many remedial measures to minimize the flashover of a porcelain insulator under pollution conditions. One such method is the application of hydrophobic coatings such as Room Temperature Vulcanizing Silicone Rubber on the surface of ceramic insulators. Laboratory testing of coated insulators has been carried out based on the solid layer method and by the inclined plane tests at constant voltage to evaluate the RTV coatings withstands capability against tracking and erosion. The performance of the coatings was assessed by monitoring the leakage current on the insulator surfaces. The applied voltage and leakage current were monitored throughout the tests. In order to optimize and economize the usage of RTV coatings various tests were performed and results are analyzed. It was possible to conclude from the test results that one fourth length of RTV coating is sufficient to withstand the pollution severity.
\end{abstract}

Index Terms: RTV, Leakage current, Pollution, Scintillation.

\section{INTRODUCTION}

Electrical power is an essential parameter for the overall development of a country. As the demand for electrical power is continuously increasing, it is observed that there is a steady growth in high voltage transmission lines for transmission of bulk power over long distances. As the level of transmission voltage is increased, switching and dynamic over-voltages and withstand ability of the insulator under polluted conditions are the most important factors, which determine the insulation level of the system. Under polluted conditions flash over occur across the insulator string leading to system outages which effects the reliability of the system. High reliability of the system is not only ensured by selecting appropriate insulation withstanding levels of various power components like power apparatus, insulators etc.., but it is also necessary to consider the pollution withstand levels of external insulation. RTV coating is one of the solution to combat pollution flashover on the existing insulator strings and insulators of related electrical equipment's like circuit breakers, switch gear, transformer, lightning arresters, support insulators, isolators etc.[1]. The coated material should have tracking and erosion property and should be able to withstand the pollution arc during scintillations [2]. Researchers have

Revised Manuscript Received on March 5, 2020.

* Correspondence Author

Rajini.H, Research Scholar, VTU, Belgaum. Assistant professor, REVA University, Bangalore, India, hrajini87@gmail.com

K.N.Ravi, Professor, HOD of EEE, Sapthagiri College of Engineering Bangalore, India, ravikn@hotmail.com

Vasudev.N, Additional Director(Retd), Central Power Research Institute, Bangalore, India, vasudev.dr@gmail.com proposed several test methods to assess the ageing characteristics and to compare the performance of different RTV coatings [3][4]. In this paper Inclined plane test is carried out on glass plate substrate and on top surface of porcelain insulators for various lengths of RTV coatings. As RTV coating is costlier this research works helps us to optimize and economize the performance of RTV coatings on insulators.

\section{EXPERIMENTAL STUDY}

\subsection{Inclined Plane Test}

In order to assess the RTV coated insulator tests were conducted on plane glass plate and RTV coated glass plate of various lengths.

This test helps for evaluation of RTV coated glass plate for various ambient conditions by measuring the surface current using liquid contaminant and inclined plane setup. Figure 1 shows the circuit diagram for Inclined plane test conducted as per IEC 60587 standards [5].

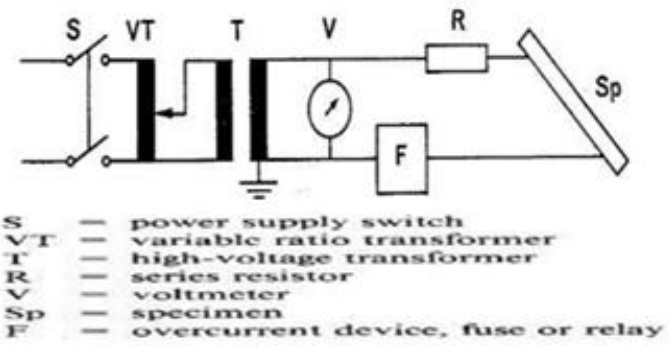

Fig. 1. Circuit diagram of inclined plane test

\subsection{Experimental Setup \& Test Procedure}

The experimental setup for inclined plane test is as shown in Figure 2.The dripping setup is filled with $1 \%$ of $\mathrm{NH}_{4} \mathrm{Cl}$ solution and the rate of flow is set according to the standards. The flow of the solution on the RTV coated glass plate is through the filter paper. The voltage is applied as per the standards for about 35 minutes. The surface leakage current of the RTV coated glass plate is monitored [6].

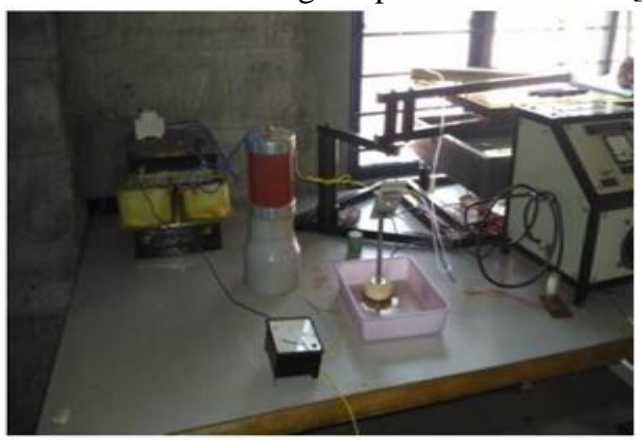

Fig. 2 Experimental Setup for Inclined Plane test

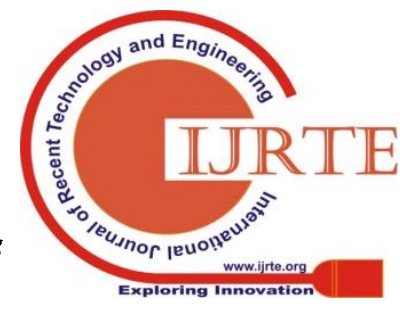


Inclined plane tests were conducted for RTV coated glass plate with removal of different lengths of RTV coating and without pollution layer. The Applied voltage and Flow rate for the tests, without removal of RTV coating to a length of 1/4th, 1/2, 3/4th and Full length removal under pollution were 6 drops per minute and $1.7 \mathrm{kV}$ respectively. The leakage current measured during the Inclined plane test for various lengths of RTV coated glass plate are tabulated in Table I and shown in Figure 3.

Table-I: Leakage current for various lengths of RTV coated glass plate without pollution

\begin{tabular}{|c|c|c|c|c|c|}
\hline $\begin{array}{c}\text { TIME } \\
\text { in } \\
\text { Min }\end{array}$ & $\begin{array}{c}\text { Fully } \\
\text { coated } \\
\text { RTV } \\
\text { in mA }\end{array}$ & $\begin{array}{c}\text { Full } \\
\text { Removal } \\
\text { of } \\
\text { RTV } \\
\text { in ma }\end{array}$ & $\begin{array}{c}\text { Half } \\
\text { Removal } \\
\text { of } \\
\text { RTV } \\
\text { in } \mathbf{~ m A}\end{array}$ & $\begin{array}{c}\text { 1/4 th } \\
\text { Removal } \\
\text { of } \\
\text { RTV } \\
\text { in } \mathbf{~ m A}\end{array}$ & $\begin{array}{c}\text { 3/4 th } \\
\text { Removal } \\
\text { of } \\
\text { RTV } \\
\text { in } \mathbf{~ m A ~}\end{array}$ \\
\hline 0 & 1.8 & 7.2 & 5 & 4.2 & 4.3 \\
\hline 5 & 1.8 & 7.6 & 3.5 & 3.8 & 3.6 \\
\hline 10 & 1.7 & 5.1 & 3.1 & 2.5 & 3.4 \\
\hline 15 & 1.7 & 3.8 & 3.0 & 2.1 & 3.2 \\
\hline 20 & 1.6 & 3.4 & 2.7 & 2.0 & 2.9 \\
\hline 25 & 1.5 & 3.1 & 2.4 & 1.8 & 2.8 \\
\hline 30 & 1.5 & 2.8 & 2 & 1.7 & 2.4 \\
\hline 35 & 1.4 & 2.6 & 1.9 & 1.6 & 2.3 \\
\hline
\end{tabular}

It can be seen from the Figure 3 that plane glass plate gives high leakage current compared to RTV coated glass plate. Even with RTV coated glass plate when RTV was removed has less leakage current value. Hence it is very clear that the difference between the currents of RTV Coating with removal of coatings for i.e., 1/4th, half, 3/4th and Full length, is less. From this it is very clear that coating can be applied on the insulators to an optimal length therefore cost of RTV can be reduced. As a safety measure the coating can be done for half the length of Glass plate.

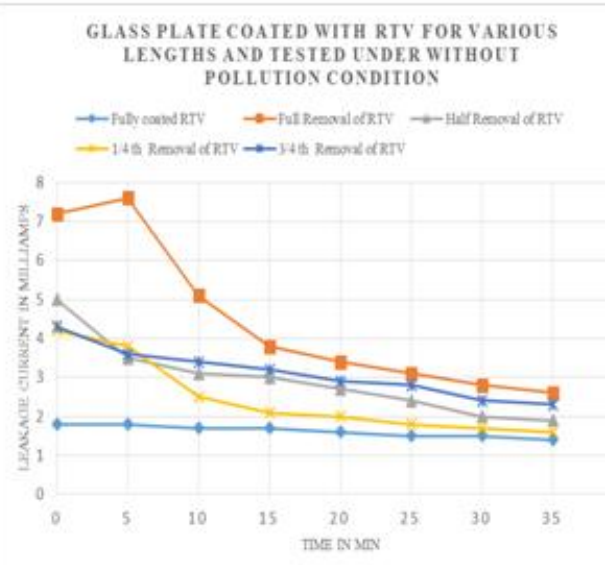

Fig .3. Leakage currents from inclined plane test conducted on glass plate coated with RTV for various lengths \& tested under without pollution

The above procedure is repeated by removing the RTV coating of different lengths i.e., half, 1/4th, 3/4th, full and polluting the layer with the kaolin powder and salt. The Applied voltage and Flow rate for without removal, 1/4th, half, 3/4th and Full removal of RTV coating under pollution were 6 drops per minute and $1.7 \mathrm{kV}$ respectively. The leakage current measured during the Inclined plane test for various lengths of RTV coated glass plate are tabulated in Table II .
Table-II: Leakage current for various lengths of RTV coated glass plate with pollution

\begin{tabular}{|c|c|c|c|c|c|}
\hline $\begin{array}{c}\text { TIME } \\
\text { in Min }\end{array}$ & $\begin{array}{c}\text { Fully } \\
\text { coated } \\
\text { RTV } \\
\text { in } \mathbf{~ m A ~}\end{array}$ & $\begin{array}{c}\text { Full } \\
\text { Removal } \\
\text { of } \\
\text { RTV } \\
\text { in } \mathbf{~ m A}\end{array}$ & $\begin{array}{c}\text { Half } \\
\text { Removal } \\
\text { of } \\
\text { RTV } \\
\text { in mA }\end{array}$ & $\begin{array}{c}\mathbf{1 / 4} \\
\text { Removal } \\
\text { of } \\
\text { RTV } \\
\text { in } \mathbf{~ m A ~}\end{array}$ & $\begin{array}{c}\text { i/4 } \\
\text { Remova } \\
\text { of } \\
\text { RTV } \\
\text { in } \\
\text { mA }\end{array}$ \\
\hline 0 & 1.8 & 6.2 & 2.8 & 3.5 & 3.0 \\
\hline 5 & 1.8 & 4.2 & 2.4 & 2.1 & 3.0 \\
\hline 10 & 1.7 & 5.3 & 2.3 & 1.6 & 3.1 \\
\hline 15 & 1.7 & 6.1 & 2.1 & 1.1 & 2.9 \\
\hline 20 & 1.6 & 5.9 & 1.9 & 0.8 & 3 \\
\hline 25 & 1.5 & 5.4 & 1.1 & 0.6 & 3.1 \\
\hline 30 & 1.5 & 4.5 & 1.0 & 0.5 & 3.0 \\
\hline 35 & 1.4 & 3.8 & 0.6 & 0.3 & 2.9 \\
\hline
\end{tabular}

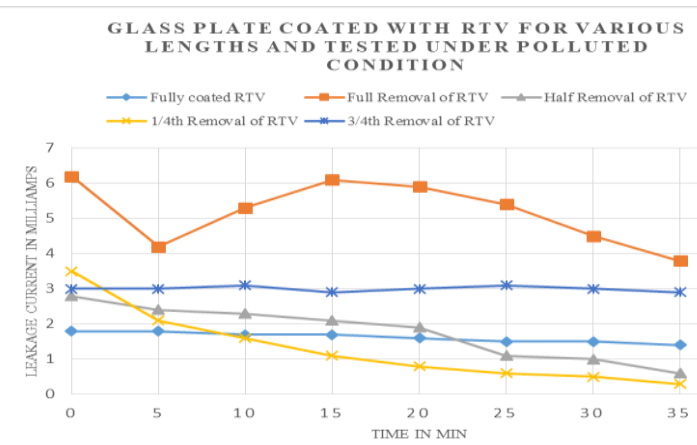

Fig .4.Leakage currents from inclined plane test conducted on glass plate coated with RTV for various lengths \& tested under with pollution

Figure 4 shows that leakage current on polluted glass plate with RTV coating are generally high. This may be due to the fact that currents are flowing on polluted surface. The above graph shows the decrease in the leakage current in $1 / 4$ th pollution compared to other configurations like half, 3/4th . The sample without removal of RTV coating was drawing lesser current.

Figure 5 shows the RTV coated glass plate with 1/4th, 3/4th removal of RTV with pollution used for inclined plane test.

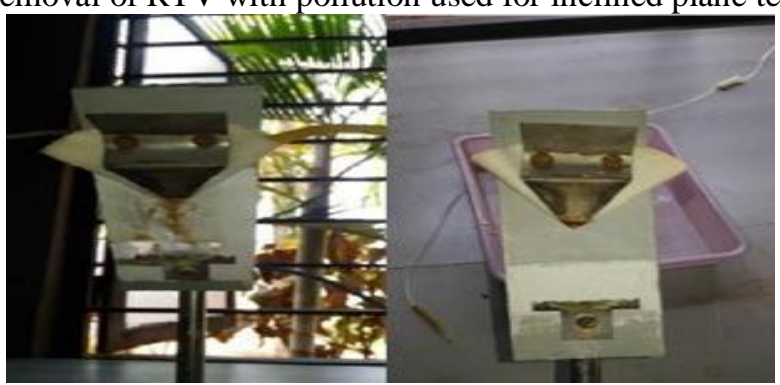

Fig . 5. RTV coated glass plate with $1 / 4^{\text {th }}, 3 / 4^{\text {th }}$ removal of RTV coating and Polluted

\section{TEST ON RTV COATED CERAMIC INSULATOR}

Ceramic insulators were subject to similar tests with and without RTV coatings, also for various lengths of RTV coatings after obtaining the 
results from glass plate model [7]. Figure 6 shows the schematic diagram for testing insulators.

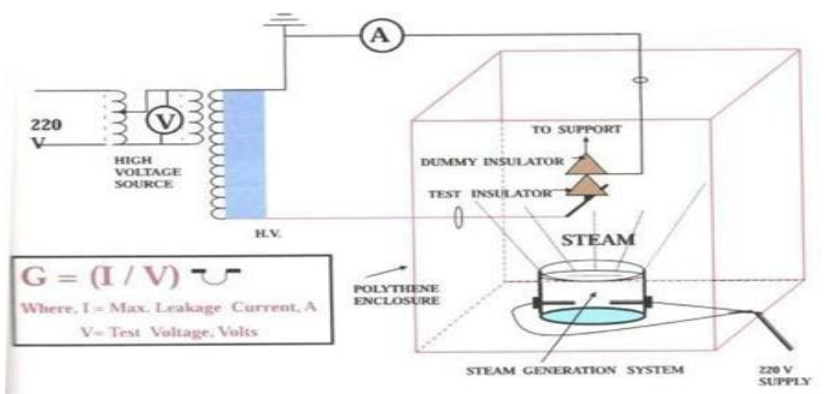

Fig.6. Schematic diagram showing the arrangements for test on insulators

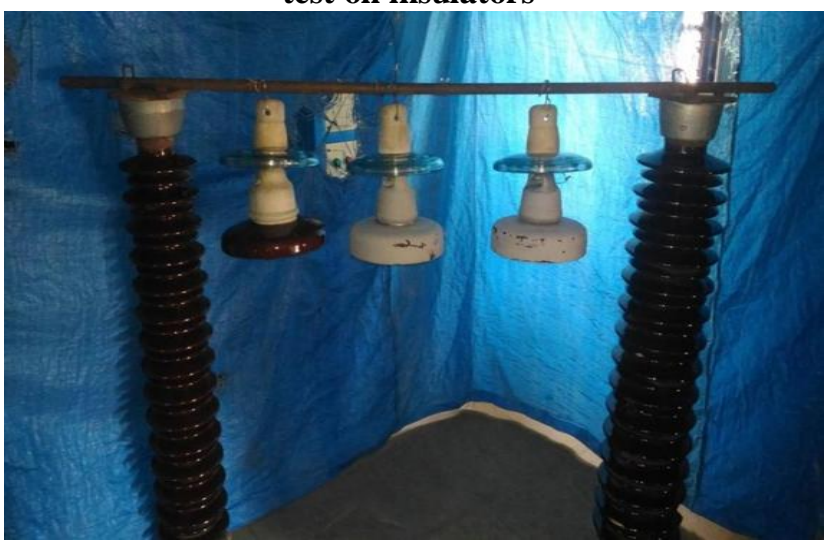

Fig .7. Experimental setup for testing uncoated, RTV coated ceramic insulators

The experimental setup is as shown in Figure 7. Three insulators were subjected to test in which one of the insulator was uncoated, second one was RTV coated and third one was subjected to experiments for various lengths of RTV coatings on top surface. Tests on these insulators were carried out with and without pollution. Clean fog method of testing was adopted for the above experiments [8]. The pollution level was in medium range and surface conductivity was about 2.8 $\mathrm{S} / \mathrm{m}$. The water heater is switched onto generate fog and the input voltage $(2.5 \mathrm{kV})$ is applied as per BIS 60507 standards [9]. Leakage currents were monitored for every 5 th minutes on uncoated, RTV coated ceramic insulators. The leakage current readings measured on uncoated and RTV coated Ceramic insulator tested under without pollution are tabulated in Table III and shown in Figure 8.

Table- III: Leakage current on Ceramic Insulator uncoated, RTV coated and tested without pollution

\begin{tabular}{|c|c|c|}
\hline $\begin{array}{c}\text { TIME } \\
(\mathbf{m i n})\end{array}$ & $\begin{array}{c}\text { CERAMIC insulator } \\
\text { uncoated } \\
(\boldsymbol{\mu} \mathbf{A})\end{array}$ & $\begin{array}{c}\text { CERAMIC INSULATOR } \\
\text { with RTV coated } \\
(\boldsymbol{\mu} \mathbf{A})\end{array}$ \\
\hline 0 & 60 & 40 \\
\hline 5 & 40 & 30 \\
\hline 10 & 40 & 30 \\
\hline 15 & 50 & 40 \\
\hline 20 & 50 & 40 \\
\hline 25 & 50 & 40 \\
\hline 30 & 40 & 40 \\
\hline 35 & 50 & 40 \\
\hline
\end{tabular}

When coated and uncoated insulators are not polluted then a small difference in the leakage current is observed from the above Figure 8.

In second set of experiment where RTV coating were removed for 1/4th of the top surface length and tested under without pollution [10]. The leakage current readings measured on uncoated, RTV coated, 1/4th removal of RTV coating on Ceramic insulator tested under without pollution are tabulated in Table IV and shown in Figure 9.

Table- IV: Leakage current on Ceramic insulators uncoated,RTVcoated, 1/4th length removal of RTV coating and tested without pollution

\begin{tabular}{|c|c|c|c|}
\hline $\begin{array}{l}\text { TIME } \\
\text { (min.) }\end{array}$ & $\begin{array}{c}\text { CERAMIC } \\
\text { insulator } \\
\text { uncoated } \\
(\mu \mathrm{A})\end{array}$ & $\begin{array}{c}\text { CERAMIC } \\
\text { insulator } \\
\text { with Fully } \\
\text { coated RTV } \\
(\mu \mathrm{A})\end{array}$ & $\begin{array}{c}\text { TEST } \\
\text { SAMPLE with } \\
1 / 4^{\text {th }} \text { removal of } \\
\text { RTV coating } \\
(\mu \mathrm{A})\end{array}$ \\
\hline 0 & 50 & 40 & 40 \\
\hline 5 & 40 & 40 & 30 \\
\hline 10 & 40 & 40 & 30 \\
\hline 15 & 40 & 40 & 40 \\
\hline 20 & 20 & 10 & 10 \\
\hline 25 & 20 & 10 & 10 \\
\hline 30 & 30 & 40 & 40 \\
\hline 35 & 20 & 20 & 20 \\
\hline
\end{tabular}

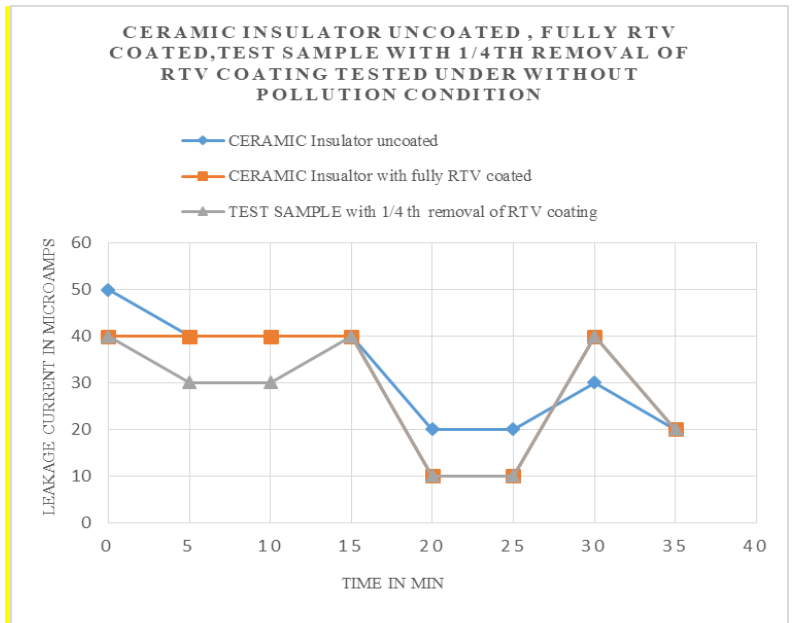

Fig.9. Leakage currents on ceramic insulators uncoated,RTVcoated,1/4th length removal of RTV coating tested without pollution

There is no much difference in leakage current between the insulators under unpolluted condition is observed from fig 9. In third set of experiment where RTV coating were removed for $1 / 2$ of the top surface length and tested under without pollution [11][12]. The leakage current readings measured on uncoated, RTV coated, 1/2 removal of RTV coating on Ceramic insulator tested under without pollution are tabulated in Table V and shown in Figure 10.

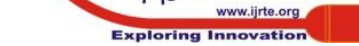


Table-V: Leakage current on ceramic insulators uncoated, RTV coated 1/2 length removal of RTV coating and tested without pollution

\begin{tabular}{|c|c|c|c|}
\hline $\begin{array}{c}\text { TIME } \\
(\mathbf{m i n} .)\end{array}$ & $\begin{array}{c}\text { CERAMIC } \\
\text { insulator } \\
\text { uncoated } \\
(\boldsymbol{\mu A})\end{array}$ & $\begin{array}{c}\text { CERAMIC } \\
\text { insulator } \\
\text { with Fully } \\
\text { coated RTV } \\
(\boldsymbol{\mu A})\end{array}$ & $\begin{array}{c}\text { TEST } \\
\text { SAMPLE with 1/2 } \\
\text { removal of RTV } \\
\text { coating } \\
(\boldsymbol{\mu A})\end{array}$ \\
\hline 0 & 4260 & 50 & 50 \\
\hline 5 & 4140 & 50 & 50 \\
\hline 10 & 4060 & 50 & 50 \\
\hline 15 & 3900 & 50 & 50 \\
\hline 20 & 3600 & 50 & 50 \\
\hline 25 & 4100 & 50 & 50 \\
\hline 30 & 3900 & 60 & 50 \\
\hline 35 & 3600 & 60 & 50 \\
\hline
\end{tabular}

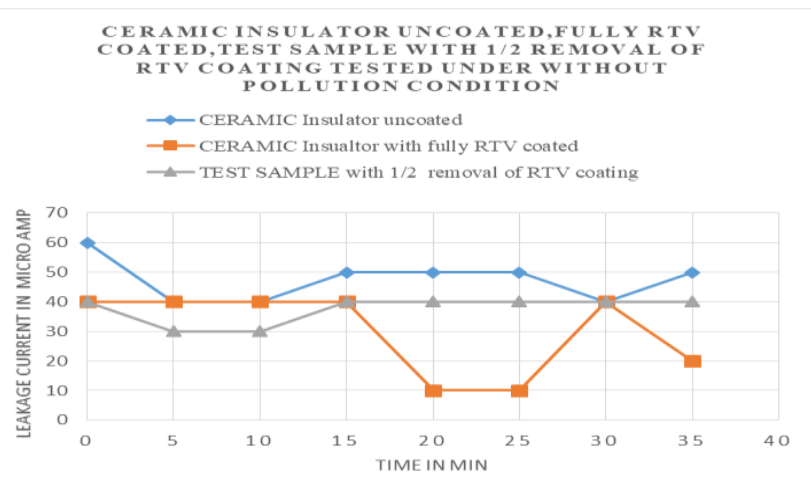

Fig. 10. Leakage currents on ceramic insulators uncoated, RTVcoated \& 1/2 length removal of RTV coating tested without pollution

Figure 10 shows that same performance is obtained even when RTV coatings were removed for $1 / 2$ of the top surface length.Experiment was also conducted on uncoated, RTV coated and RTV coating removed (1/2 of the top surface length) insulators with pollution [13]. The leakage current readings are tabulated and shown in Table VI and Figure 11.

Table-VI: Leakage current on ceramic insulators uncoated, RTV coated 1/2 length removal of RTV coating and tested with pollution

\begin{tabular}{|c|c|c|c|}
\hline $\begin{array}{c}\text { TIME } \\
(\mathbf{m i n} .)\end{array}$ & $\begin{array}{c}\text { CERAMIC } \\
\text { insulator uncoated } \\
(\boldsymbol{\mu A})\end{array}$ & $\begin{array}{c}\text { CERAMIC } \\
\text { insulator with } \\
\text { Fully coated } \\
\mathbf{R T V} \\
(\boldsymbol{\mu A})\end{array}$ & $\begin{array}{c}\text { TEST } \\
\text { SAMPLE with } \\
\mathbf{1 / 2} \text { removal of } \\
\text { RTV coating } \\
(\boldsymbol{\mu A} \mathbf{)}\end{array}$ \\
\hline 0 & 40 & 40 & 40 \\
\hline 5 & 30 & 40 & 30 \\
\hline 10 & 50 & 40 & 30 \\
\hline 15 & 20 & 40 & 40 \\
\hline 20 & 40 & 10 & 10 \\
\hline 25 & 50 & 10 & 10 \\
\hline 30 & 60 & 40 & 40 \\
\hline 35 & 30 & 20 & 20 \\
\hline
\end{tabular}

Fig. 11 Leakage currents on ceramic insulators uncoated, RTVcoated\& 1/2 length removal of RTV coating tested with pollution.
Figure 11 shows that there is very small difference between RTV coated and insulator with RTV coating removed ( $1 / 2$ of the top surface length).It can also be observed that leakage current flowing through uncoated ceramic insulator is high compared to RTV coated and insulator with $1 / 2$ length removal of RTV coating.Test was repeated on uncoated, RTV coated, 3/4th length removal of RTV coating on top surface of ceramic insulator with pollution [14] [15].The leakage current readings are tabulated and shown in Table VII and figure 12.

Table VII: Leakage current on ceramic insulators uncoated, rtv coated 3/4th length removal of rtv coating and tested with pollution

\begin{tabular}{|c|c|c|c|}
\hline $\begin{array}{l}\text { TIME } \\
\text { (min.) }\end{array}$ & $\begin{array}{c}\text { CERAMIC } \\
\text { insulator } \\
\text { uncoated } \\
(\mu \mathrm{A})\end{array}$ & $\begin{array}{l}\text { CERAMIC insulator } \\
\text { with Fully coated } \\
\text { RTV } \\
(\mu \mathrm{A})\end{array}$ & 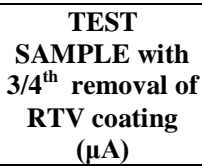 \\
\hline 0 & 1400 & 60 & 60 \\
\hline 5 & 1420 & 60 & 60 \\
\hline 10 & 1390 & 60 & 60 \\
\hline 15 & 1030 & 60 & 60 \\
\hline 20 & 1200 & 60 & 60 \\
\hline 25 & 1120 & 60 & 60 \\
\hline 30 & 1140 & 60 & 70 \\
\hline 35 & 1120 & 90 & 90 \\
\hline
\end{tabular}

CERAMIC INSULATOR UNCOATED,FULLY RTV COATED,TEST SAMPLE WUTH 3/4TH REMOVAL OF RTV COATING TESTED UNDER WITH POLLUTION CONDITION

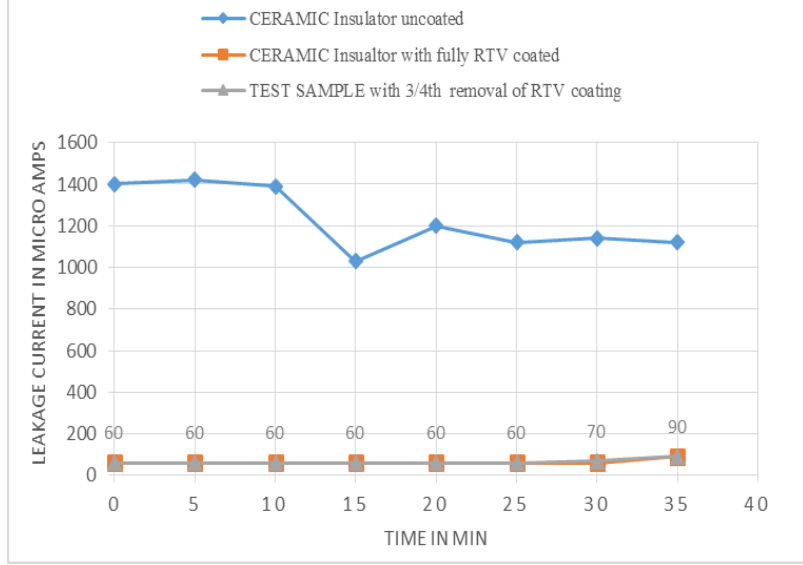

Fig. 12 Leakage currents on ceramic insulators uncoated, RTVcoated\& 3/4th length removal of RTV coating tested with pollution

Figure 12 shows that uncoated insulator was drawing higher current than RTV coated insulators. Again there is no difference in performance of RTV coated insulator with 3/4thof top surface removed and fully coated insulator.

Figure 13 shows how RTV coating is removed for half, 3/4th length in insulator and polluted with Kaolin powder. These insulators were used for experimental study to know the performance of RTV coatings on Insulators for various lengths in polluted condition.

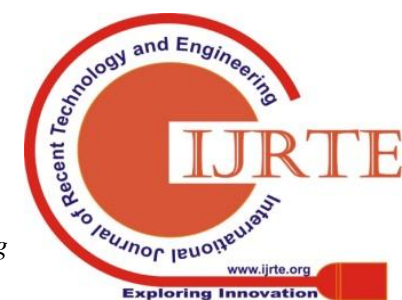



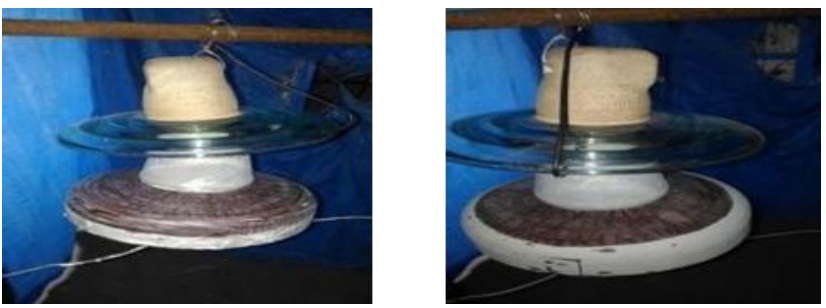

Fig. 13 Insulator with pollution and half, 3/4th removal of RTV coating

\section{RESULTS}

\section{Part A}

Results of Inclined plane test on glass plate with RTV coating (with and without pollution)

a. Leakage current of 1/4th length of RTV removal and $1 / 2$ length removal of RTV is less compared to fully coated RTV on glass plate insulator with pollution.

b. Leakage current of 1/4th length of RTV removal and $1 / 2$ length removal of RTV is less compared to fully coated RTV on glass plate insulator without pollution.

\section{Part B}

Results of experimental study on insulator with RTV coating (with and without pollution)

a. A small difference in the leakage current is observed between uncoated and RTV coated insulators without pollution.

b. Leakage current on 1/4th length removal of RTV coating, 1/2 removal of RTV coating is less compared to uncoated and RTV coated insulator without pollution.

c. It is observed that uncoated insulator draws high leakage current in pollution condition. But Leakage current on 1/4th length removal of RTV coating, 1/2 removal of RTV coating is less compared to uncoated and RTV coated insulator with pollution.

\section{CONCLUSION}

Based on the experiments carried on glass plate and insulators with RTV coating (with and without pollution) following are the major conclusions

a. The results from inclined plane test carried out on glass plate for various lengths of RTV coating and tested for with and without pollution showed that 1/4th length of RTV coating carries lower surface current and performance is similar to fully RTV coated glass plate.

b. The results from inclined plane test carried on insulator for various lengths of RTV coating and tested for with and without pollution also showed that $1 / 4$ th length of RTV coating carries lower surface current and performance is similar to fully RTV coated insulator.

c. Tests carried out on both glass plate and insulator shows that 1/4th length of RTV coating is sufficient to withstand and perform similar to fully coated RTV.

The results of the above experiments are encouraging such that the cost on RTV coatings can be reduced effectively. This will help in reducing the line outages due to pollution flashover.

\section{REFERENCES}

1. Gorur, R. S., Cherney, E. A.," RTV silicone rubber coatings for outdoor Insulators"..,IEEE Transactions on Power Delivery, Vol. 6 , No. 5, Dec 1999.W.-K. Chen, Linear Networks and Systems (Book style).Belmont, CA: Wadsworth, 1993, pp. 123-135.

2. R.SGorur,J.Montesinos,L.Varadadesikan,S.Simmons\&M.Shah .," A Laboratory Test for tracking \&erosion Resistance of HV outdoor Insulation",IEEE Transactions on Power Delivery, Vol. 11, No. 1, Dec 1997.

3. Gorur, R. S., Cherney, E. A., de Tourrcil, C., Dumora D., Harmon R., and Hervig H., "Protective coatings for improving contamination performance of outdoor high voltage ceramic insulators," IEEE Transactions on Power Delivery, Vol. 10, No. 2, April 1995

4. HuiDeng,Hackam, R.,Cherney, E. A.," Inflence of thickness, substratetype,amount of silicone fluid \& solvent type on the electrical performance of RTV silicone rubber coatings," IEEE Transactions on Power Delivery, Vol. 11, No. 1, April 1996.

5. Devendranath et al.: "A leakage current \& charge in RTV coated Insulators under pollution condition..,"IEEE Transactions on Dielectrics and Electrical Insulation, Vol. 9, No. 2, April 2002.

6. Meyer et al.,: "Corelation of damage, dry band arcing energy \& temperature in Inclined plane testing of silicone rubber for outdoor insulation.,"IEEE Transactions on Dielectrics and Electrical Insulation, Vol. 11, No. 3, June 2004

7. HaifengGao,ZhidongJia, Zhicheng Guan, Liming Wang \& Keneg Zhu ..," Investigation on Field aged RTV coated Insulator used in heavily contaminated areas", IEEE Transactions on Power Delivery, Vol. 22, No. 2, April 2007

8. A. Naderian et al.: "Aging characteristics of RTV silicone rubber insulator coatings."IEEE Transactions on Dielectrics andElectrical Insulation, Vol. 15, No. 2, April June 2008

9. Suwarno\&FariPratomosiwi ..., Application of RTV silicone rubber coating for improving performances of ceramic outdoor insulator under polluted condition"International Conference on Electrical Engg\& Informatics 5-7 August 2009, Selangor, Malaysia

10. E.ACherney,A.ElHag,S.Li,R.SGorur,L.Meyer,I.Ramirez,M.Marzinto o, J-M George, "RTV Silicone Rubber Pre- coated CeramicInsulators for Transmission lines", IEEE Transactions on Power Delivery, Vol. 20 No. 1, April 2013.

11. Johnny Wardman, Thomas Wilson, Stewart Hardie, Pat Bodger, "Influence of Volcanic Ash Contamination on the flashover voltage of HVAC oudoor Suspension Insulators", Vol. 21 No. 3, April 2014.

12. Massimo Marzinotto, Edward Cherney, Giovanni Mazzanti..," RTV precoated cap \& pin toughened glass insulators- A wide experience in the Italian overhead transmission system..," Annual report conference in Electrical insulation \& Dielectric phenomenon 2015.

\section{AUTHORS PROFILE}

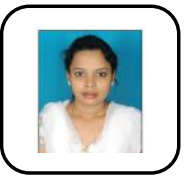

Rajini. H received her B.E degree in Electrical \& Electronics Engineering from Sri Krishna Institute of Technology in 2008 and MTech degree in power system from The National Institute of Engineering, Mysore in 2012. She is currently working as Assistant professor in School of Electrical \& Electronics Engineering in REVA University Bangalore.Andpursueing her Phd in VTU, Belgaum. Her research interests are Ageing \& pollution performance of Insulators in High Voltage etc. Email: hrajini87@gmail.com, Mob: 7619413497

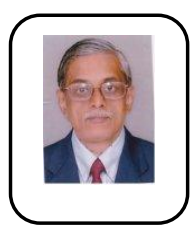

Dr.Ravi.K.N did his BE degree in Electrical \& Electronics Engineering from UVCE, Bangalore, ME in High Voltage Engineering from IISC and PhD in High voltage Engineering from IISC. He is currently working as Professor \& HOD in Sapthagiri College of Engineering, Bangalore. He is currently guiding $\mathrm{PhD}$ in the area of High voltage.He is specialized in the field of Design of electrical Insulation from the point of view of pollution under AC \&Dc voltages, Pollution Ageing of Dc insulators, pollution study on AC and DC insulators \& arresters. He is the member of IEEE.

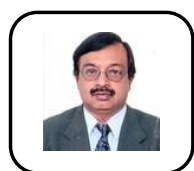

Dr. Vasudev. $\mathbf{N}$ did his BE from R. V. College of Engineering, Bangalore, ME in power system fromUniversity of Mysore and $\mathrm{PhD}$ from Bangalore University. He is retiredadditional director from CPRI, Bangalore. He is currently guiding $\mathrm{PhD}$ and $\mathrm{MSc}$ 
engineering students in the area of High voltage. He is the member of IEEE, member of review committee for DSIR for development of composite insulators, member of Technical Committee for Rural electrification corporation for formulation of specification for composite insulators, CIGRE National committee member for overhead lines 